\title{
Fuzzy Logic based Decision Support System for Mass Customization
}

\author{
N.R.Gilke \\ K. J. Somaiya College of \\ Engineering, Vidyavihar(E), \\ Mumbai, India
}

\author{
S.S.Mantha \\ All India Council for Technical \\ Education, New Delhi, India
}

\author{
G. T. Thampi \\ Thadomal Shahani College of \\ Engineering, Bandra (W), \\ Mumbai,India
}

\begin{abstract}
Intelligent decision support system is one of the key enabler of successful implementation of mass customization (MC). Manufacturing enterprises in the business of mass customization ought to leverage software embedded with optimized intelligent and intuitive algorithms for decision making at each stage of company's functioning from designing through to product life cycle management.. Artificial Intelligence (AI) is an example of such available tools that enables composite atomization of technological and organizational preparation of manufacture of customized products. In MC the requirement given by the customer may be semi structured or nonstructural, incomplete, contradictory or difficult to formalize. The manufacturer offers customer interactive tools on the web to configure their product and assist in placing an order. The fuzzy logic tool (FLT) can be used to assist the customer to finalize their requirements from the options given from the manufacturer. In automotive, customization has many facets like color, material, electronic instrumentation, seats, engine, brakes, etc. The paper describes the application of FLT to improve the decision support system of MC. The feasibility and effectiveness of the decision support system using FLT are empirically validated by case study implementation of engine selection and braking system as features of automobile.
\end{abstract}

Keywords: Mass customization, Artificial intelligence, Fuzzy logic, Decision support system

\section{Introduction}

Globalization of world economy and growth of competition in the market imposed pressure on the companies to increase customer's satisfaction as well to enlarge their market share by improving their products in terms of quality, price, variety, safety, delivery time, flexibility etc. The role of design and development department of an organization is to translate the needs of the diverse customers

Davis proposed the concept of Mass Customization and stated that one can simultaneously mass produce, distribute and deliver customized goods and services [1]. The concept of MC was further expanded by Pine [2]. In mass customization, low costs are achieved primarily through economies of scope. Piller [3] found that information is the main enabler and therefore new information technologies are the major drivers of MC. According to Frutos and Borenstien [4] "An MC system is highly dependent on well designed information systems that provides direct link among the main agents involved in the customization process, namely customer, company, and supplier". The MC can be defined as set of interlink activities that are necessary to capture individual requirement to translate into physical product, which is then produced and delivered to the customer satisfying his needs with lowest cost possible with near mass production efficiency.

With increasing popularity of the internet and broadband, it is possible to let consumers be involved in the design of the product that reflect their preferences and personalities [5]. The company's abilities to track individual customer preferences have been turbocharged by the Internet [6]. Mass customization starts with understanding customer's individual requirements [7]. One of the prerequisites for realizing mass customization is the effective definition of customer requirements. Companies must initiate a dialogue with individual customers to help them articulate their needs [8].

To facilitate the customer inputs into the design phase of product development the techniques used are: surveys, focus groups and customer interviews. Generally complete picture of customer preferences are not captured by these techniques [9]. Actually application-specific portion of the product is designed by the user [10].

From the manufacturer's point of view, the requirements given by the customers are fuzzy, uncertain and abstract. They are often poorly understood by the manufacturer, resulting in tedious or even invalid configuration task based on vague superposition and implicit inferences. The fuzzy logic tool is used to assist the customer to finalize their requirements from the options given by the manufacturer. Fuzzy analysis based, fuzzy sets theory [11] is capable of dealing with qualitative or imprecise input from the designer by describing the performance of each criteria with some linguistic terms, such as good, poor, medium etc. Fuzzy logic is powerful problem solving methodology which provides simple way to draw definite conclusion from vague, ambiguous, or imprecise information. Fuzzy logic resembles human decision making with its ability to work from approximate data and find precise solution.

In this paper, the fuzzy logic tool is used as a decision support system to translate the imprecise requirements of the customers while customizing the product to the specific requirement. The AI based MC system is designed for selecting the automobile components such as engine and brake system. The organization of this paper is as follows. Section 2 reviews artificial intelligence based customization system. Section 3 describes fuzzy based mass customization system for selection of automobile, section 4 presents discussion. conclusion and future work are presented in section 5 . 


\section{Artificial Intelligence based Customization System}

The knowledge of most customers is incomplete and vague due to complexity of modern automobiles. The uncertainty nature of the customer requirements leads us to seek a solution in Artificial Intelligence based Customization System as shown in the Figure 1, particularly the fuzzy logic model. The manufacturer offers customers a huge number of customizable options and the customer has to select combination of features to suit their requirements. Fuzzy Logic Tool can be used to translate the non specific requirements given by the customer to specific requirement of the product and it can be used to assist customer for customizing the product.

Customer gives the input to the transducer, which converts this input to the feature extractor block. The feature extractor reduces the data by measuring certain properties that selects one parameter from the given set of parameters. These features are then passed to a Fuzzy based classifier that evaluates the evidence presented and makes a final decision. The prototype model is then generated. If the customer is not satisfied with the prototype model displayed on GUI, then he/she can modify the input. The process is repeated till the customer gets final product as per his requirement. Thus the pattern recognition and classification technique is used for customizing the product.

\section{Fuzzy based Mass customization systems for selection of automobile components}

Figure 2 describes the conceptual proposed block diagram of fuzzy based Mass customization systems for selection of engine and brakes. The customer has option to select input parameters as a fuel (Petrol/Diesel/Gas) and speed for selection of engine and break type with its sophistication for selection of brakes. The output of the fuzzy based decision support system is the Engine type, brake type and price as shown in Figure 2.

The flow diagram for selection of engine is shown in Figure 3. Based on the need the customer gives the input parameters specified by the manufacturer in the Graphic User Interface (GUI) based system. The AI based system provides feasible and optimal solution

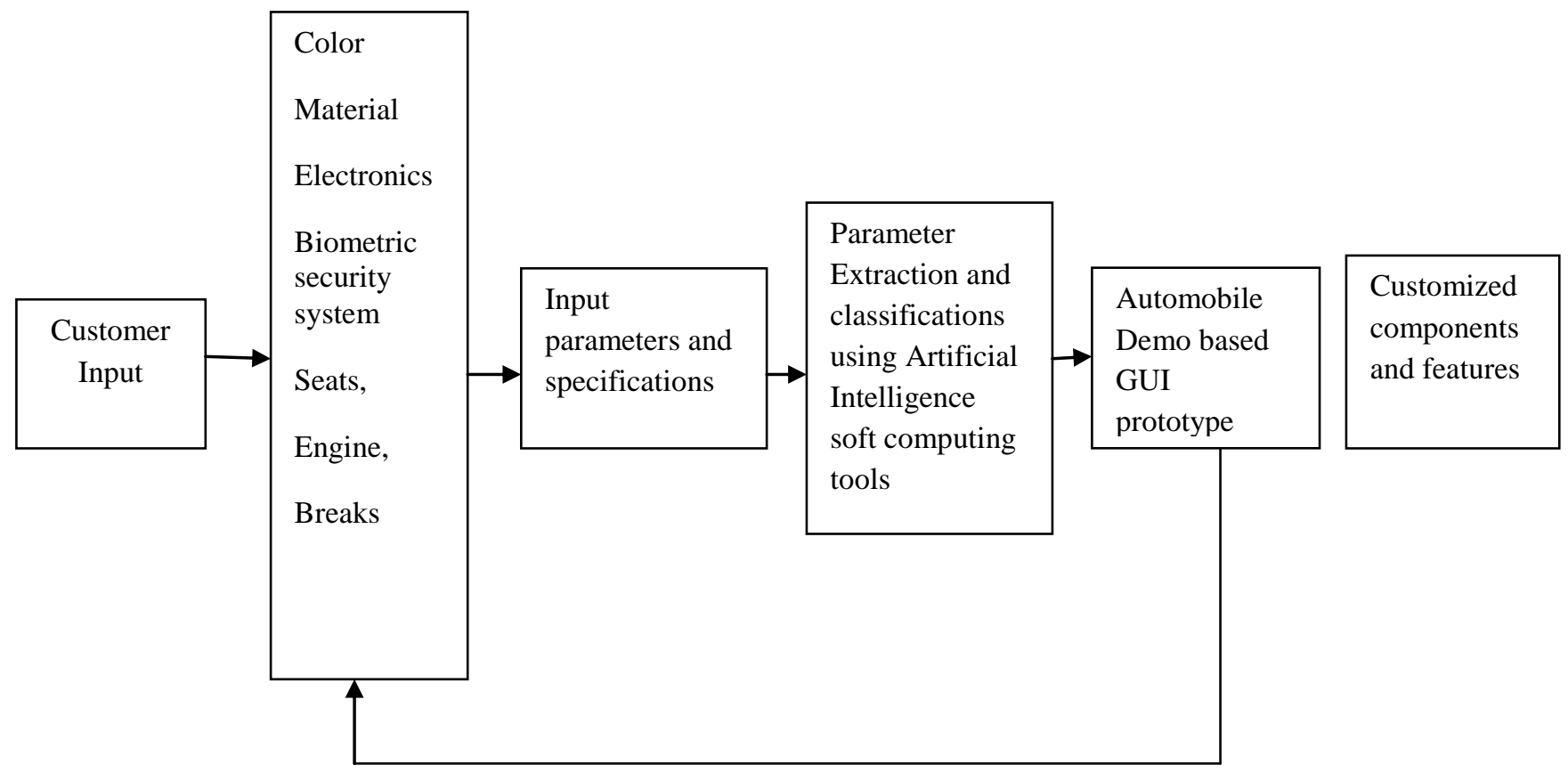

Figure 1: Artificial Intelligence based Customization System

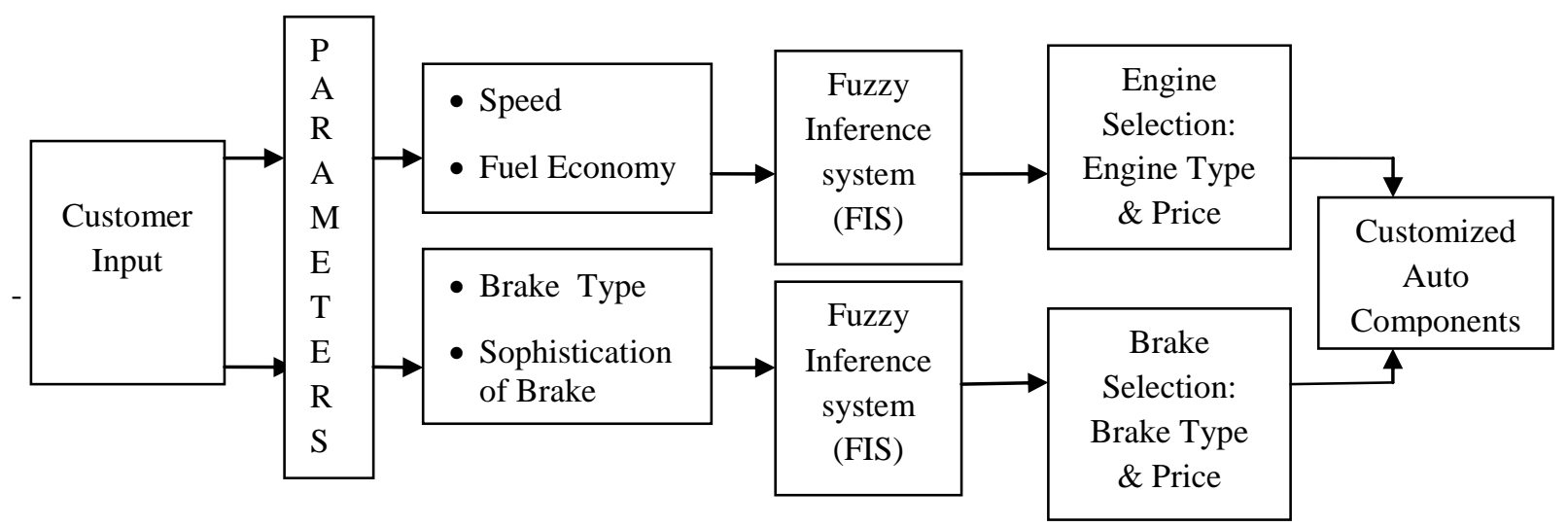

Figure 2: Fuzzy Based Mass customization System 


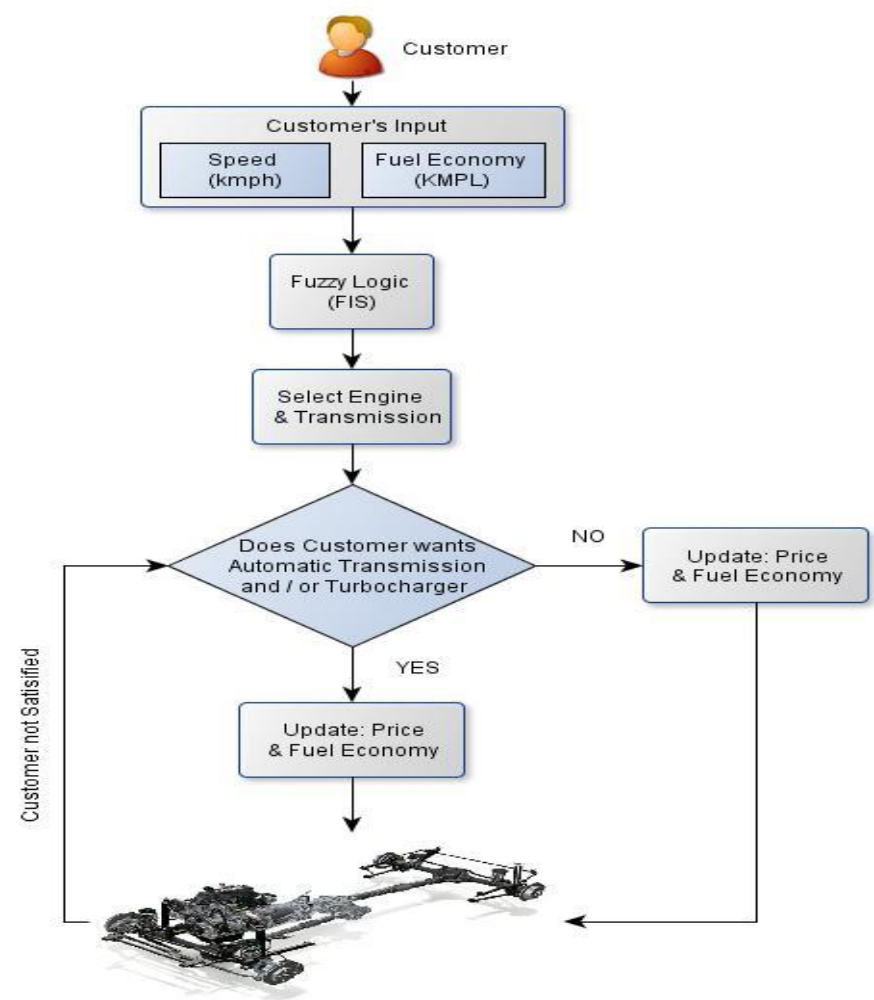

Figure 3: Flowchart for Engine \& Transmission Selection.

\subsection{Fuzzy logic based Engine Selection.}

Customer specifies the input parameters such as fuel economy and speed in the GUI based system provided by the manufacturer. The input parameters are expressed as fuzzy numbers. They are represented as fuzzy sets. Figure 4 shows the membership function of the fuzzy variable fuel economy which are divided into four grades namely, DM- Doesn't Matter, LI-Less Important, I-Important, MI-Most Important. Figure 5 shows the membership function of the fuzzy variable Speed which is divided into four grades namely, S-Slow, F-Fast, VF-Very Fast, FF-Fastest. Triangular membership function is chosen for each fuzzy set. The four membership functions for each of the two inputs make maximum of sixteen combinations. Therefore sixteen IF-THEN rules defined for fuzzy controller as shown in Table 1. The system is simulated in MATLAB 7.9.
The defuzzification is the process where the membership functions are sampled to find the grades of membership; then the grades of membership(s) are used in the fuzzy logic equation(s) and an outcome region is defined. From this, the output is deduced. The Rule viewer is used for viewing the FIS, which enables the user to understand how each rule contributes towards the output. The Rule viewer of engine selection is shown in Figure 6, which also aids the user to find out if the fuzzy system components are behaving in the right manner or not.

The surface viewer generates and plots the surface maps for the system. Figure 7 represents the surface view for engine selection. The $\mathrm{x}$-axis and $\mathrm{y}$-axis respectively represents the input parameters speed and fuel economy while the $\mathrm{z}$-axis represents the output engine selection. Surface viewer is $\begin{array}{llll}\text { strictly a read only } & \text { a }\end{array}$

\begin{tabular}{|l|l|l|l|l|}
\hline Speed & Doesn't Matter & Less Important & Important & Most Important \\
\hline Slow & $1.2 \mathrm{~L}$ Diesel & $1 \mathrm{~L}$ Petrol & $1 \mathrm{~L}$ Petrol & $1 \mathrm{~L}$ Petrol \\
\hline Fast & $1.4 \mathrm{~L}$ Petrol & $1.2 \mathrm{~L}$ Diesel & $1.2 \mathrm{~L}$ Diesel & $1.2 \mathrm{~L}$ Diesel \\
\hline Very Fast & $1.6 \mathrm{~L}$ Diesel & $1.4 \mathrm{~L}$ Petrol & $1.6 \mathrm{~L}$ Diesel & $1.4 \mathrm{~L}$ Petrol \\
\hline Fastest & $2 \mathrm{~L}$ Petrol & $1.6 \mathrm{~L}$ Diesel & $2 \mathrm{~L}$ Petrol + Hybrid & $2 \mathrm{~L}$ Petrol + Hybrid \\
\hline
\end{tabular}

Table 1: Engine Selection Rule Matrix 


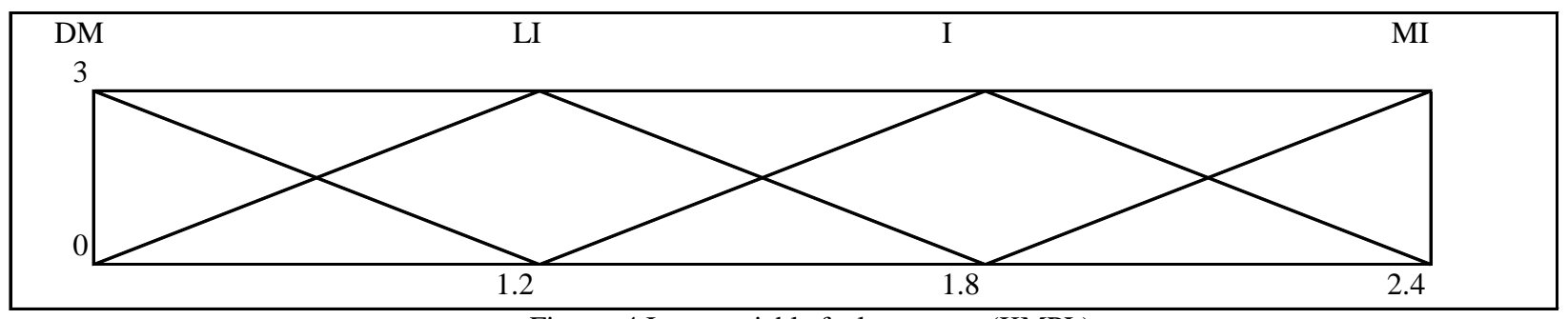

Figure: 4 Input variable fuel economy (KMPL)

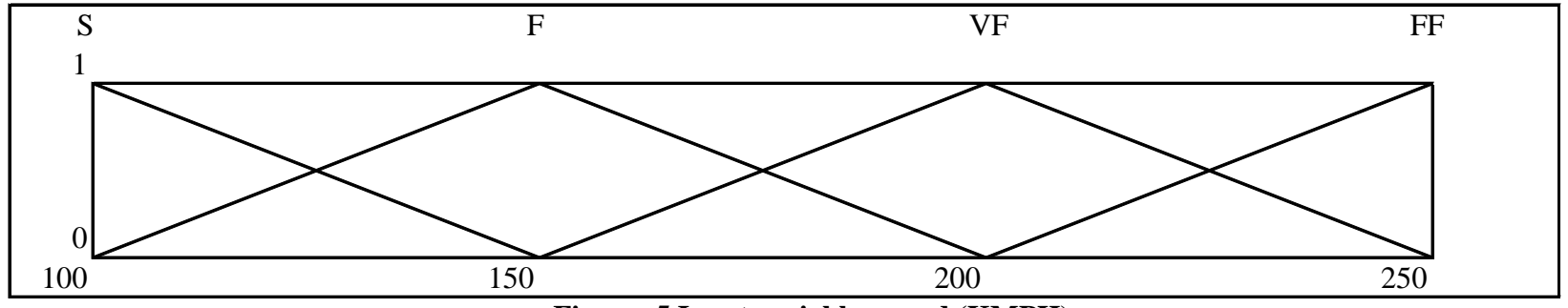

Figure: 5 Input variable; speed (KMPH)

\subsection{Fuzzy logic based selection of Braking System}

Fuzzy logic based brake selection module is shown in Figure 8.As per the choice given by the company for the selection of the available braking system with regards to the brake type and level of sophistications, the customers gives input parameters to the fuzzy logic based mass customization

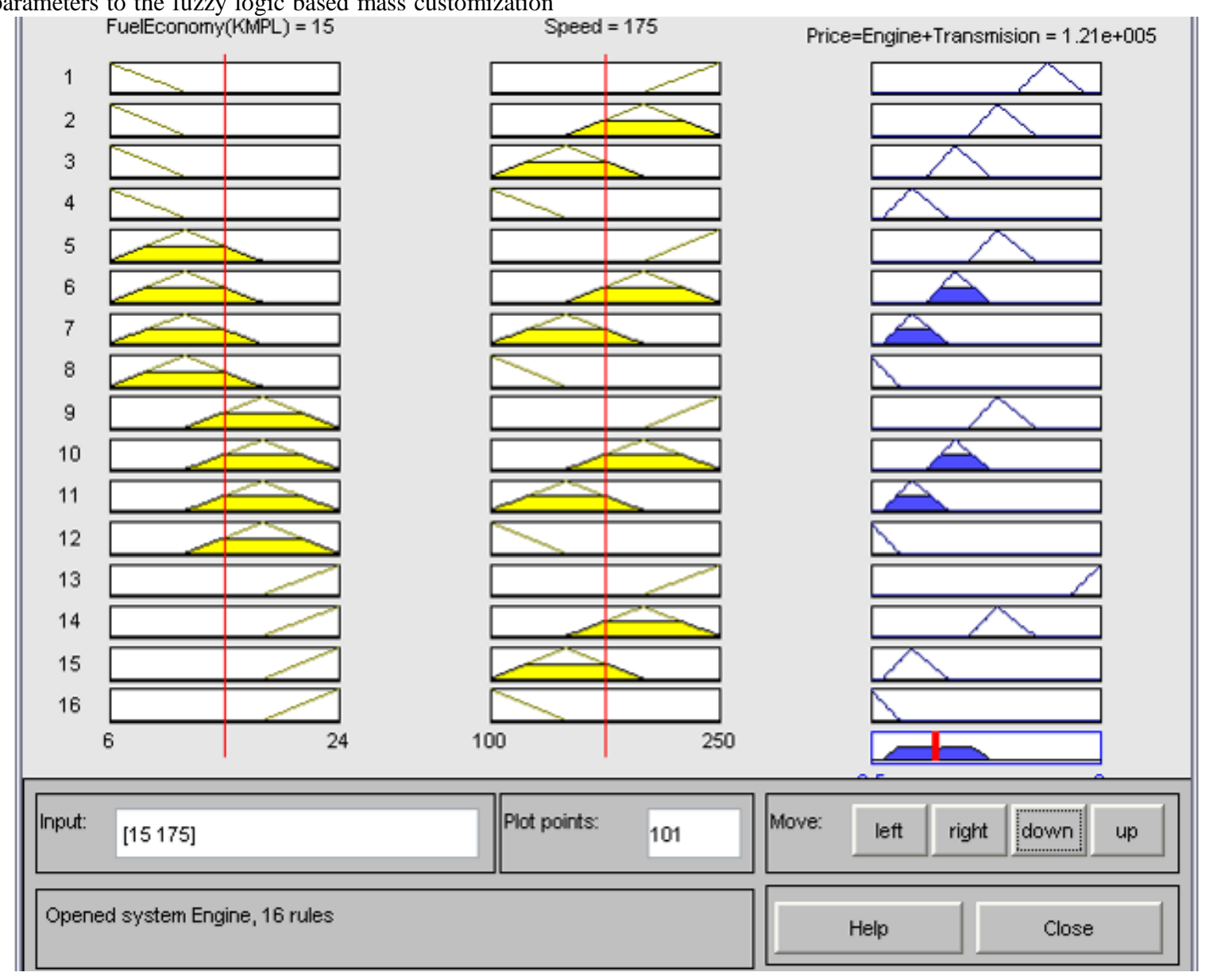

system. For the requirement of the customer for a particular type of braking system and its sophistication, the customer will have two criteria namely, Brake Type and its sophistication (the inclusion of Antilock Braking System (ABS) Or Electronic Braking System (EBS) Or an integration of ABS and EBS).

Figure:6: Defuzzification (Rule Viewer window for Engine Selection) 


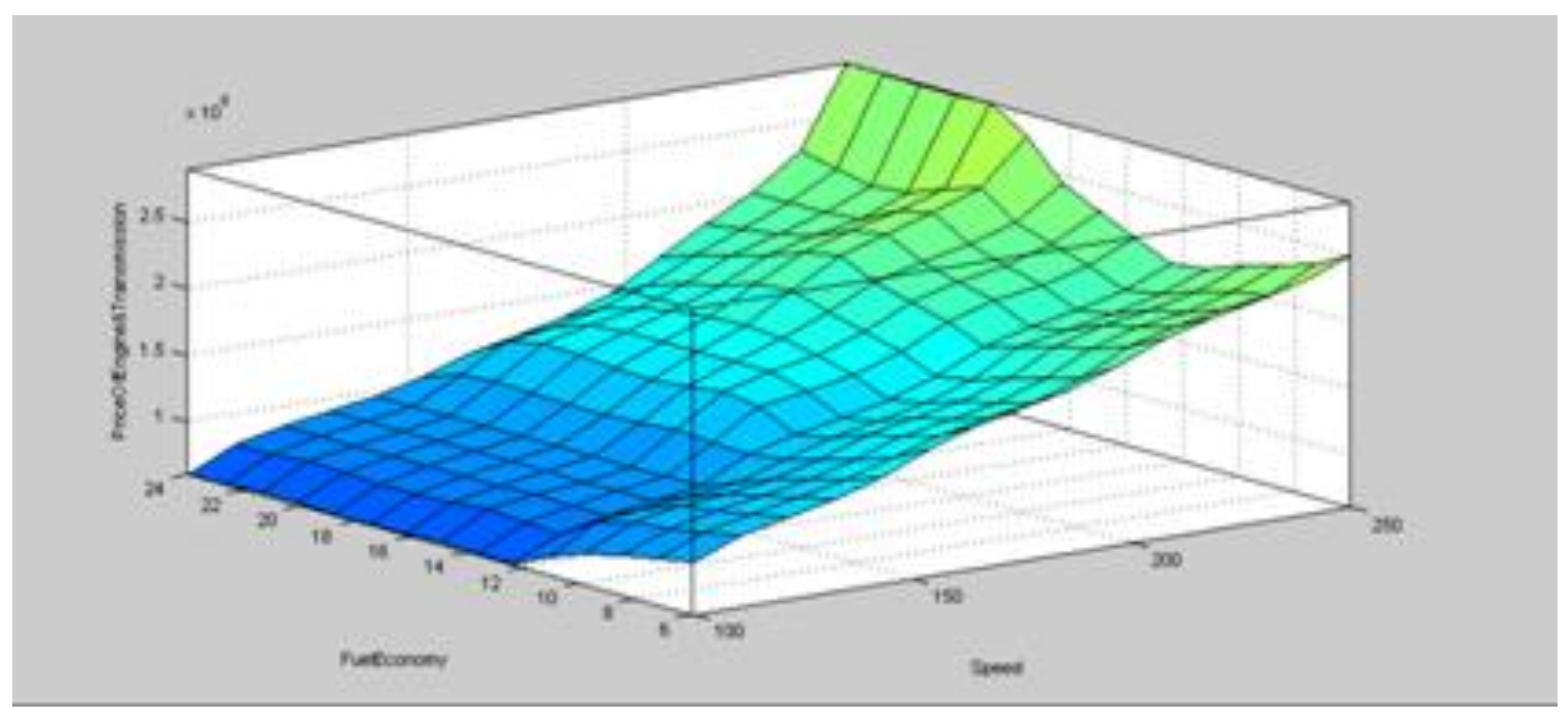

Figure: 7 Surface plots for engine selection

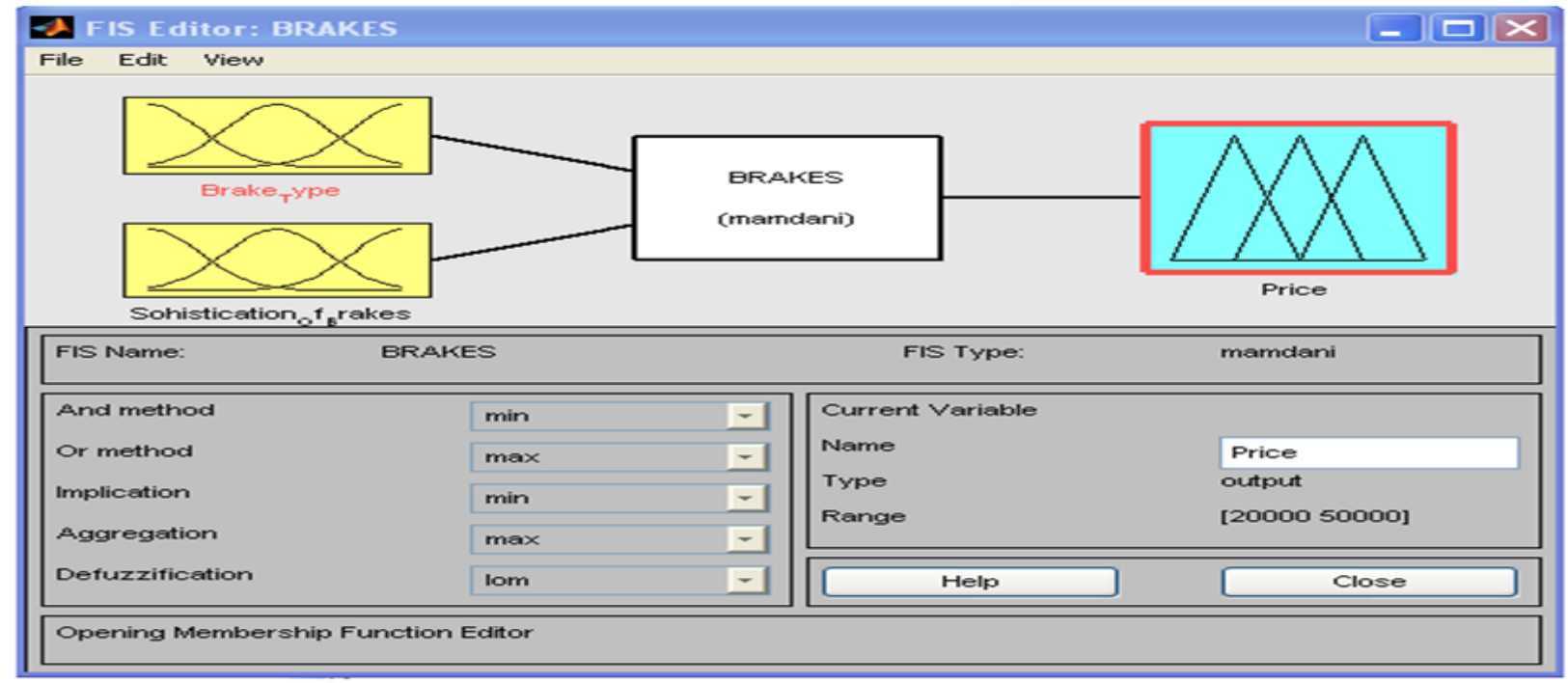

Figure 8: Fuzzy logic based brakes selection module

\begin{tabular}{|l|l|l|l|}
\hline \multicolumn{1}{|c|}{ Brake Type } & Both Drum & $\begin{array}{l}\text { Front Disc \& Rear } \\
\text { Drum }\end{array}$ & Both Disc \\
\hline Sophistication of Brakes & Low & Moderate & High \\
\hline Traditional & Moderate & High & Very High \\
\hline $\begin{array}{l}\text { Anti lock Braking System (ABS) } \\
\text { (EBS) }\end{array}$ & High & Very High & Very High \\
\hline
\end{tabular}

Table 2: Rule Matrix for Braking System

Figure 9 shows the membership function of the fuzzy variable brake type which are divided into three grades namely, BD-Both drum, FDRD-Front disc rear drum, BDC-Both disc brakes. Figure 10 shows the membership 
function of the fuzzy variable Sophistication of Brake which is divided into three grades namely, T-- Traditional, ABSAnti lock Braking System, ABS \& EBS - Anti lock Braking System and Electronic Braking system. The input varies in the range of 0 to 1 . The three membership functions for each of the two inputs make maximum of nine combinations. Table 2 gives the rule matrix for the braking system. The Rule viewer and the surface view of braking system are shown in Figure $11 \& 12$ respectively.

The braking system provides Price as an output. The four types of outputs descriptors are namely: Low, Moderate, High and Very High. The Price range for selection of braking system varies from rupees twenty thousand to fifty thousand

\section{Discussion.}

The decision support system proposed in this paper is used to assist in selecting the best alternative when the inputs are vague or qualitative. It is a highly flexible and interactive IT system that is designed to support decision making when the problem is not structured. The system can be used where a statistical database does not exist for the criteria or where the criteria themselves are qualitative in nature. The system helps to automate the processes of decision making. The system developed is user-friendly, and supported by graphics.

The proposed system for engine and brake system selection has been developed for two criteria namely fuel economy and speed for engine and brake type and its sophistication for braking system. The system can be extended for multiple criteria. The Decision Support System with FLT developed overcomes the ambiguity in the decision making as compared to the Analytical Hierarchical Process (AHP). One of the shortcomings addressed by FLT is that the traditional AHP is unable to cope with the subjective, vague and imprecise properties in people's decision making. Being software based system the FLT has less number of manual calculations that would be required to examine the attributes as compared to traditional AHP which is more time consuming however the above limitation of AHP can be resolved by using the software expert-choice.

\section{Conclusion \& Future Work}

In this paper AI based decision support system for mass customization is presented. The Fuzzy customization system developed features linguistic input such as slow, fast, very fast and fastest and only requires the definition of two parameters and hence has the potential to attract customers. The feasibility and effectiveness of the decision support system using FLT are empirically validated by case study implementation of engine selection and braking system as features of automobile. The system can be further expanded by incorporation of additional parameters. The fuzzy logic system for each customizable feature can be developed and with proper GUI the customer can specify various parameters and select best features fulfilling his needs. The system developed will benefit the auto-manufacturers as well as customers.

\section{Acknowledgement:}

The authors are very much thankful to anonymous reviewer for their valuable comments, which significantly improved the quality of the paper.

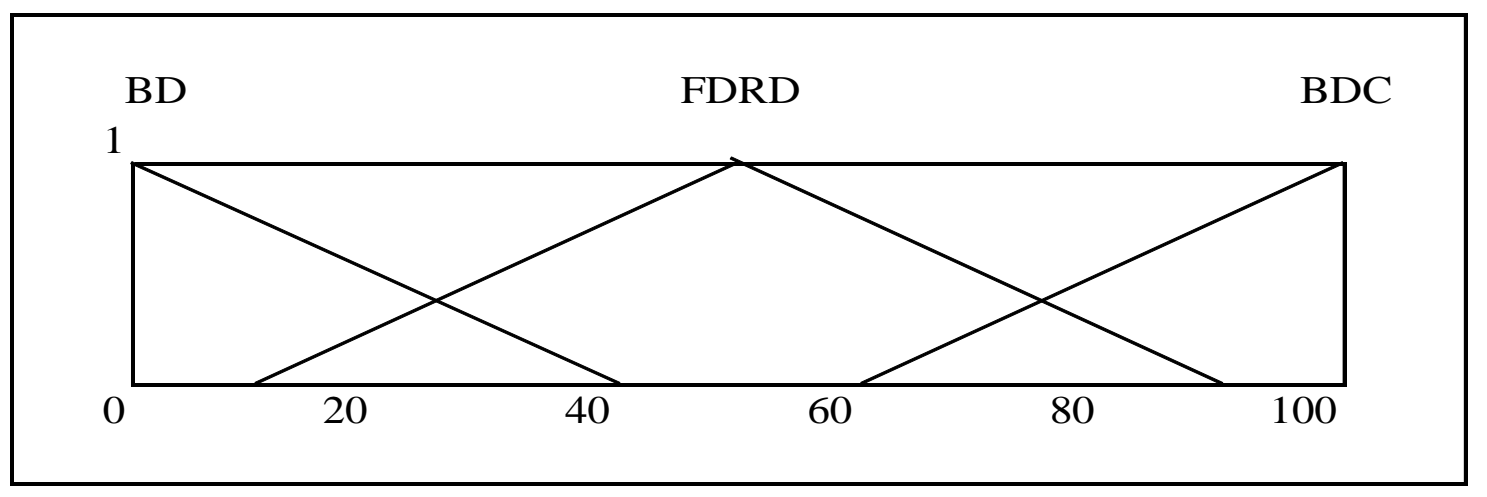

Figure: 9 Input variable brake type

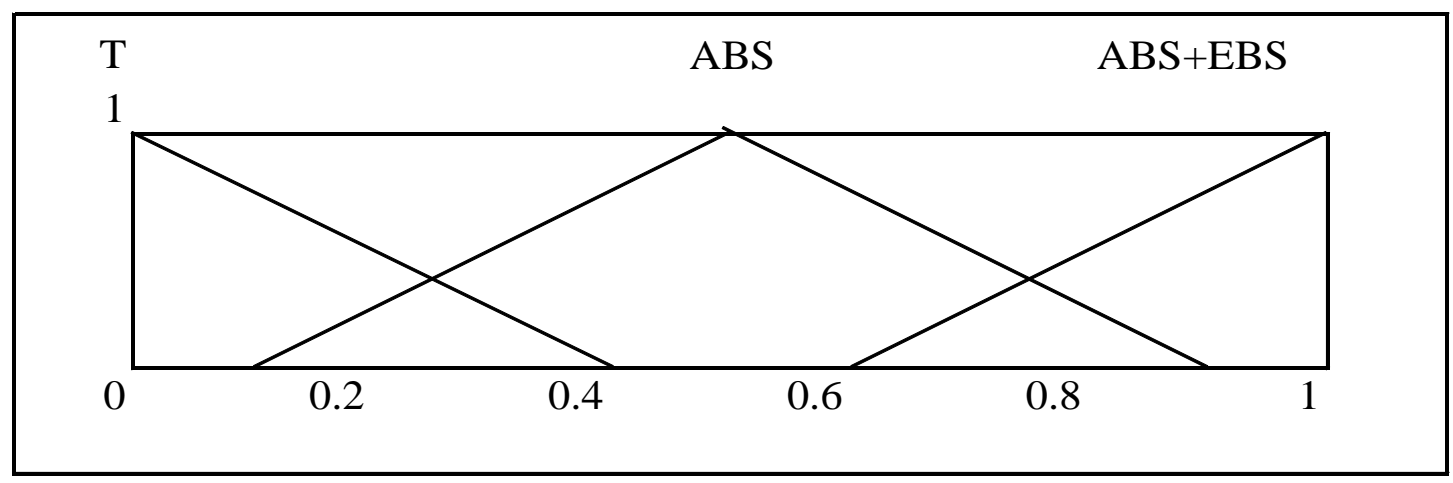

Figure:10 Input variable for sophistication of brake 

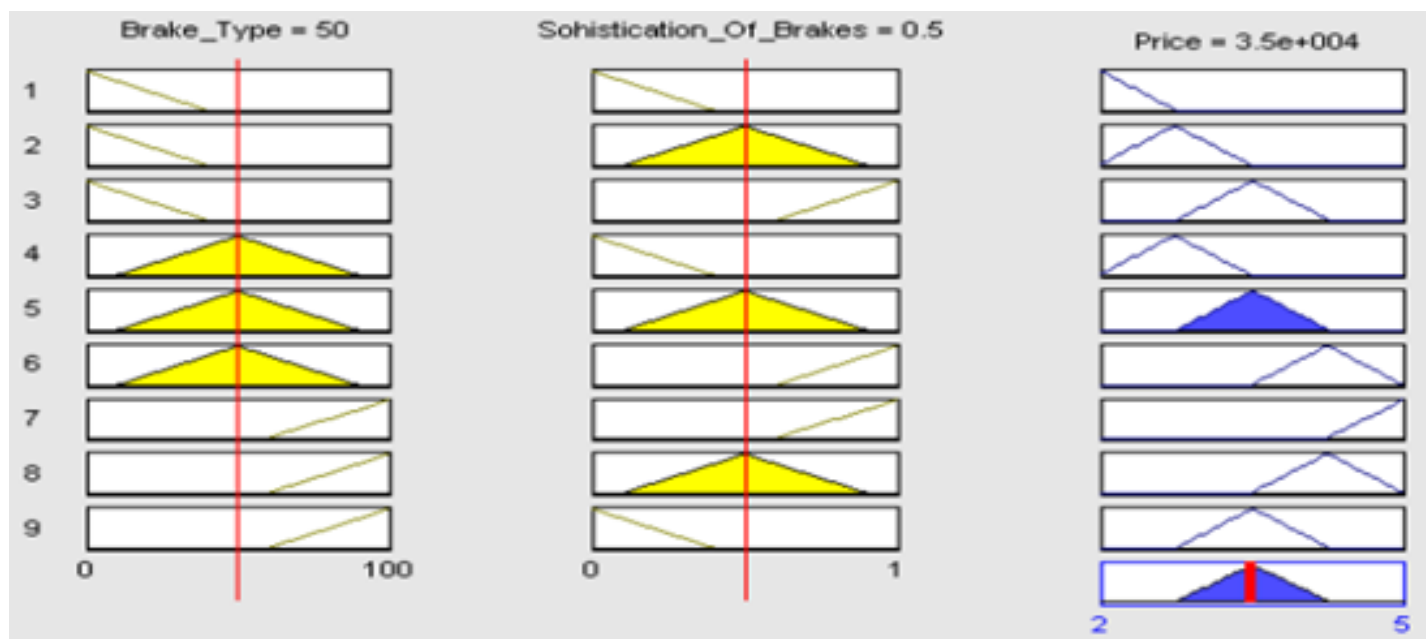

Fig 11: Defuzzification (Rule Viewer window for braking System)

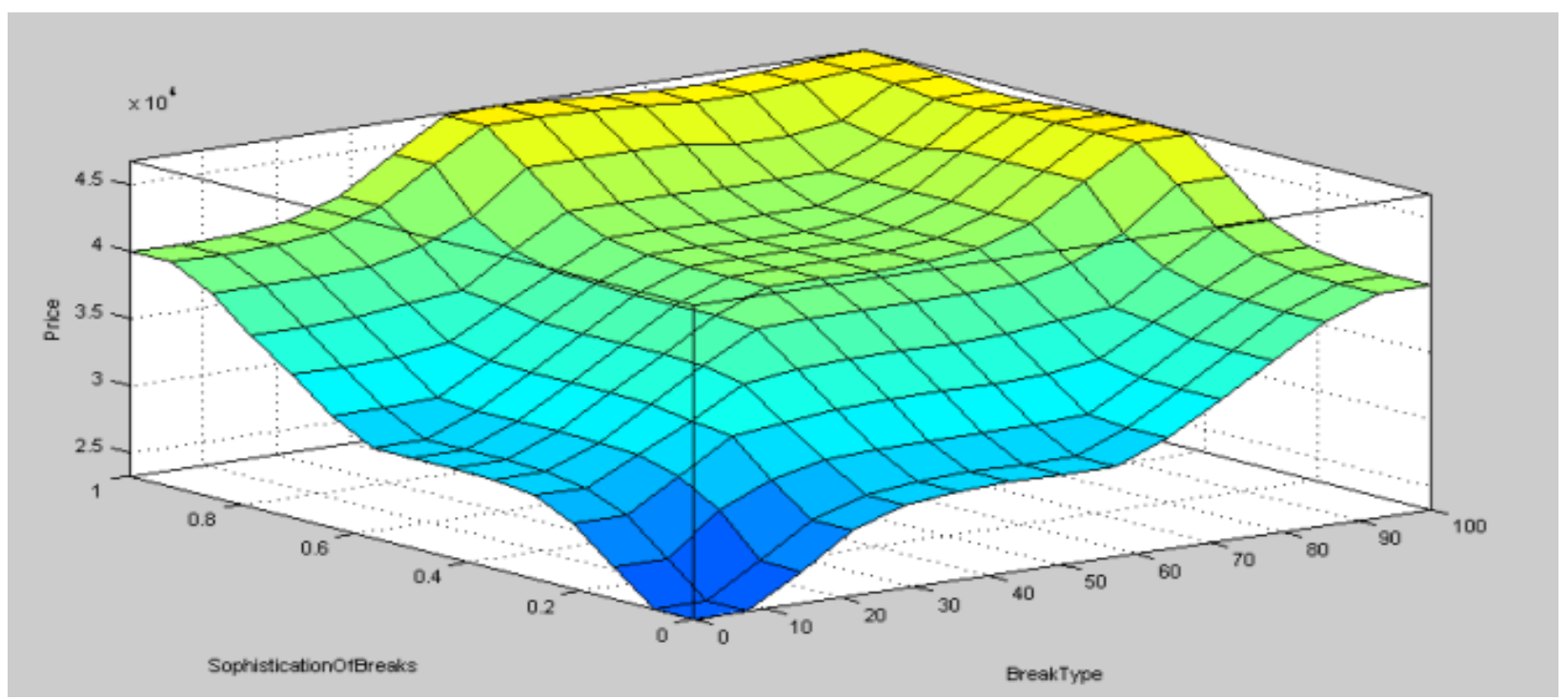

Figure: 12 Surface plots for braking system

\section{References}

[1] Devis, S., (1997), Future perfect,. Perseus Books Group, New York.

[2] Pine, B.J., (1999), Mass customization: the new frontier in business competition. Harvard Business School Press, UK.

[3] Piller, F.T., (2002), Customer Interaction and Digitization - A Structured Approach to Mass Customization. Moving into Mass Customization: Information Systems and Management Principal, Part II" Springer, Berlin. pp 119-137.

[4] Frutos, J.D.and , Borenstien, D. (2004), A Framework To Support Customer-Company Interaction In Mass Customization Environments. Computers. Industries 54, pp115-135.

[5] Chen, Y. H; Wang, Y.Z; and Wong, M. H. (2001). "A Web-Based Fuzzy Mass Customization system.” Journal of Manufacturing Systems(v 20, n4) pp 280-287
[6] Dewang, R.; Jing,B.; Seidmann,A. (2000)."Adoption of Internet-based product customization and pricing strategies." Proc. Of Hawai International Conference on System Sciences, Jan 4-7, 2000, pp 135.

[7] Fulkerson,B.(1997). "A response to dynamic change in the market place." Decision Support Systems (v21, n3), pp 199-214.

[8] Proops, S. (1996). "Mass Customization. Stimulating the knowledgeable market." IEE Colloquium (Digest) (v181, n10), pp 1/1-1/6.

[9] Brown, M.G.; Hitchcock, D.E.; Willard M.L..(1994).Why TQM Fails and What to Do About It. Burr Ridge;IL: Irwin Professional Publishers.

[10] Von Hippel, E. (1998).” Economics of product development by users: the impact of 'sticky' local information." Management Science (v44, n4),pp 629-644.

[11] Zadeh, L. A., (1965), "Fuzzy sets," Informat. Control, vol. 8 pp. 338-353. 